\title{
O PROBLEMA DO LIXO GERADO PELAS EMBALAGENS DE PIZZA NA CIDADE DE SÃO PAULO
}

\author{
Paula Bueno - Faculdade Metropolitanas Unidas, São Paulo \\ Mestranda do curso de Administração, na FMU \\ Antonio Felipe Cora - Faculdade Metropolitanas Unidas, São Paulo \\ Mestranda do curso de Administração, na FMU
}

Prof. Doutor Alexandre Formigoni

\section{Resumo}

São Paulo gera em média 18 mil toneladas de lixo diariamente entre lixo comum (resíduos domiciliar), público ou especial, sendo que o resíduo domiciliar representa 12 mil toneladas/dia.

O site da Prefeitura de São Paulo informa que os trabalhos de coleta são executados pelas concessionárias Ecourbis e Loga, que percorrem diariamente uma área de $1.500 \mathrm{~km}^{2}$ onde 11 milhões de pessoas são beneficiadas e onde mais de três mil pessoas trabalham no recolhimento desses resíduos com 500 caminhões além de outros veículos especializados para coleta de resíduos de saúde (Dados coletados no site da Prefeitura de São Paulo www.capital.sp.gov.br em outubro e novembro de 2016 e atualizado em janeiro de 2017).

Com esses números impressionantes é preciso analisarmos para onde vai todo esse material, que destino é dado a ele e se essa é realmente a melhor destinação a ser dada para esse lixo. 
Esse estudo pretende trazer à tona a problemática do volume de lixo da cidade de São Paulo fazendo um recorte na categoria de resíduos sólidos, levantando a quantidade de lixo gerada especificamente pelas embalagens de pizza (só em São Paulo são consumidas 570 mil pizzas por dia que correspondem a 57\% do volume total do país), analisando qual o destino final é dado para essas embalagens, como e onde são descartadas e ainda propondo uma reflexão de qual seria o melhor destino para elas no intuito de minimizar o impacto ambiental que provocam.

Para isso foi realizada uma pesquisa exploratória através de um levantamento bibliográfico e de dados secundários extraídos dos anais da Prefeitura de São Paulo e da PGIRS - Plano de Gestão Integrada de Resíduos Sólidos da Cidade de São Paulo. Tomado conhecimento de um volume de lixo tão impressionante e nocivo para a cidade e que cresce exponencialmente esse estudo propõe não uma mudança no consumo da pizza, alimento tão intrínseco à cultura do paulistano e do brasileiro, mas sim uma nova forma de acondicioná-la e que possa ser reutilizada e reciclada diminuindo significativamente o impacto na natureza.

Palavras-chave: Lixo, Resíduos Sólidos, Coleta Seletiva de Lixo, Aterro Sanitário, Reciclagem, Embalagem De Pizza.

\section{Abstract}

São Paulo generates an average of 18 thousand tons of garbage daily between common trash (household waste), public or special, and the household waste represents 12 thousand tons / day.

The website of the City of São Paulo informs that the collection works are carried out by the concessionaires Ecourbis and Loga, which daily cover an area of $1,500 \mathrm{~km}^{2}$ where 11 million people are benefited and where more than three thousand people work in the collection of these residues with 500 Trucks and other specialized vehicles for collecting health waste (Data collected on the website of the City of São Paulo www.capital.sp.gov.br in October and November of 2016 and updated in January of 2017).

With these impressive numbers we must analyze where all this material is going, what destiny is given to it and if this is really the best destination to be given to this garbage. 
This study aims to bring to light the problem of the volume of garbage in the city of São Paulo by cutting the category of solid waste, raising the amount of garbage generated specifically by pizza packaging (in São Paulo alone 570 thousand pizzas are consumed per day. Correspond to $57 \%$ of the total volume of the country), analyzing the final destination for these packages, how and where they are discarded and still proposing a reflection of which would be the best destination for them in order to minimize the environmental impact they cause.

So, an exploratory research was carried out through a bibliographical survey and secondary data extracted from the annals of the City of São Paulo and the PGIRS Integrated Solid Waste Management Plan of the City of São Paulo.

Aware of a volume of rubbish that is so impressive and damaging to the city that it grows exponentially, this study proposes not a change in the consumption of pizza, a food so intrinsic to the culture of São Paulo and Brazil, but a new way of packing it and which can be reused and recycled, significantly reducing the impact on nature.

Keywords: Garbage, Solid Wastes, Selective Collection of Garbage, Landfill, Recycling, Pizza Packaging.

\section{Resumen}

São Paulo genera un promedio de 18 mil toneladas de basura diaria entre basura común, pública o especial, y la basura doméstica representa 12 mil toneladas / día.

El sitio de la Ciudad de São Paulo informa que las obras de recolección son realizadas por las concesionarias Ecourbis y Loga, que cubren diariamente una superficie de $1.500 \mathrm{~km}^{2}$ donde se benefician 11 millones de personas y donde más de tres mil personas trabajan en la colección de estos residuos con 500 camiones y otros vehículos especializados para la recolección de residuos sanitarios (Dados recopilados en el sitio de la Ciudad de São Paulo www.capital.sp.gov.br en octubre y noviembre de 2016 y actualizados en enero de 2017).

Con estos números impresionantes debemos analizar dónde va todo este material, qué destino se le da y si éste es realmente el mejor destino a dar a esta basura.

El objetivo de este estudio es poner en evidencia el problema del volumen de basura en la ciudad de São Paulo, cortando la categoría de residuos sólidos, aumentando la cantidad de basura generada específicamente por el envasado de pizza (solo en São 
Paulo se consumen 570 mil pizzas por día , correspondiendo al 57\% del volumen total del país), analizando el destino final de estos paquetes, cómo y dónde son descartados y aún proponiendo un reflejo de cuál sería el mejor destino para ellos a fin de minimizar el impacto ambiental que tienen.

Así, se realizó una investigación exploratoria através de una encuesta bibliográfica y datos secundarios extraídos de los anales de la Ciudad de São Paulo y del PGIRS Plan Integral de Manejo de Desechos Sólidos de la Ciudad de São Paulo.

Consciente de un volumen de basura tan impresionante y perjudicial para la ciudad que crece exponencialmente, este estudio propone no un cambio en el consumo de pizza, un alimento tan intrínseco a la cultura de São Paulo y Brasil, sino una nueva forma de embalar y que puede ser reutilizado y reciclado, reduciendo significativamente el impacto sobre la naturaleza.

Palabras clave: Basura, Desechos sólidos, Recogida selectiva de basura, Vertedero, Reciclaje, Embalaje de pizza.

\section{Introdução}

A cidade de São Paulo gera, em média, 18 mil toneladas de resíduo sólido diariamente, popularmente conhecido como lixo, entre resíduos domiciliares, resíduos de saúde, restos de feiras livres, podas de árvores, entulho e demais resíduos recolhidos. Só de resíduos domiciliares são coletados cerca de 12 mil toneladas por dia (Dados coletados no site da Prefeitura de São Paulo www.capital.sp.gov.br em outubro e novembro de 2016 e atualizado em janeiro de 2017).

Os resíduos sólidos urbanos (RSU), também conhecidos como lixo doméstico, são aqueles gerados nas residências, no comércio ou em outras atividades desenvolvidas nas cidades.

Nestes resíduos encontram-se: papel, papelão, vidro, latas, plásticos, trapos, folhas, galhos e terra, restos de alimentos, madeira e todos os outros detritos apresentados à coleta nas portas das casas pelos habitantes das cidades ou lançados 
nas ruas. O RSU pode conter ainda alguns resíduos que podem ser tóxicos, como pilhas, baterias e outros eletrônicos que devem ter um descarte diferenciado.

No Brasil, a Lei 12.305 de Política Nacional de Resíduos Sólidos de 02 de agosto de 2010 determina as diretrizes relativas à gestão integrada e o gerenciamento dos resíduos sólidos, fazendo distinção entre o lixo que pode ser reciclado ou reaproveitado e o lixo perigoso, aquele que é rejeitado.

Atualmente o município de São Paulo utiliza três aterros para dispor os resíduos domiciliares e de varrição coletados, dois privados e um aterro funcionando sob objeto de concessão, sendo eles respectivamente: Aterro Sanitário Caieiras, Aterro Sanitário Centro de Disposição de Resíduos (CDR) Pedreira e o Aterro Sanitário Central de Tratamento de Resíduos Leste (CTL). Há também os aterros com as atividades encerradas, devido a lotação, e que se encontram em fase de monitoramento, como por exemplo, o Aterro São João, localizado na Avenida Sapopemba, que recebeu os resíduos coletados pela Ecourbis até outubro de 2009; e o Aterro Bandeirantes, localizado na Rodovia dos Bandeirantes km 26 em Perus, o qual recebeu resíduos coletados pela Loga até março de 2007. (Dados coletados no site da Prefeitura de São Paulo www.capital.sp.gov.br em outubro e novembro de 2016 e atualizado em janeiro de 2017).

Os RSUs são uma das grandes preocupações de gestores públicos municipais, pois à medida que o volume de RSUs aumenta, aumenta-se a complexidade para encontrar áreas adequadas que sirvam de aterros, e com a tendência de crescimento de geração de resíduos urbanos, aliado aos resquícios de um sistema de descarte ultrapassado, conduz aos riscos econômicos, ambientais e sociais (Thomas, 2010). Ainda que a reciclagem seja uma opção para a diminuição do volume de lixo levado aos aterros, muitos materiais ainda não podem ser reciclados, entre eles a caixa de pizza. E o volume de caixas de pizzas em São Paulo é muito expressivo conforme comentado anteriormente e quantificado abaixo. A caixa da pizza (embalagem) feita de papelão poderia ser reutilizada se não fosse a gordura do alimento que contamina esse material e impede sua reciclagem.

No Brasil, diariamente são consumidas em torno de um milhão de pizzas e aproximadamente 570 mil somente na cidade de São Paulo, o que corresponde a 57\% (Fonte: Associação das Pizzarias Unidas do Estado de São Paulo 2016). Considerando que uma caixa padrão tem 35 centímetros de comprimento, por 35 centímetros de 
largura e cinco centímetros de altura, temos um volume de lixo não reciclável e não reutilizável que deve ser considerado.

O presente trabalho tem o objetivo de analisar o volume de lixo de caixas de pizzas gerado na cidade de São Paulo, buscando um melhor entendimento da relevância do problema e soluções, ou mesmo melhorias, para este problema.

\section{Método de Pesquisa}

O objetivo geral do trabalho foi identificar qual o volume gerado pelo descarte de embalagens de pizza na cidade de São Paulo dentro dos resíduos sólidos urbanos não recicláveis. O objetivo secundário foi identificar alternativas para a diminuição do volume citado.

Esta pesquisa caracterizou-se como exploratória, visando proporcionar mais familiaridade com o problema, tornando-o explícito (Gil, 2002). Como procedimento de coletas de dados foi feito um levantamento bibliográfico e de dados secundários extraídos de várias fontes, todas citadas devidamente durante o artigo.

A coleta de dados bibliográficos foi desenvolvida a partir de artigos científicos, anais de eventos científicos e anais eletrônicos públicos, como os anais da Prefeitura de São Paulo, com levantamento documental baseado em documentos oficiais sobre resíduos sólidos urbanos, como o Decreto 7.404/2010 e a Lei 12.305 de 02 de agosto de 2010 que institui a Política Nacional de Resíduos Sólidos, alterando a Lei no 9.605, de 12 de fevereiro de 1998 e instituiu também a PGIRS - Plano de Gestão Integrada de Resíduos Sólidos da Cidade de São Paulo, além de outras fontes eletrônicas públicas disponíveis na Associação das Pizzarias Unidas, entre outros.

\section{Análise e Discussão de Dados}

\section{Definições e a Legislação Atual}

Lixo pode ser entendido como "todo material inútil, descartado, posto em local público, tudo que se joga fora. Trata-se de objeto ou substância que se considera inútil, ou cuja existência, em dado meio, é tida como nociva" (Hempe \& Noguera, 2012).

De acordo com o site da Prefeitura de São Paulo, resíduos sólidos são produtos não aproveitados das atividades humanas, sejam elas domésticas, comerciais, 
industriais e de serviços de saúde, e que por vezes podem ser aproveitados tanto para reciclagem como para sua reutilização.

O local mais adequado para a destinação dos resíduos sólidos é o aterro sanitário, onde o lixo é depositado de forma planejada. Outra porção do lixo é destinada aos aterros controlados, com critérios menos rígidos, mas com procedimentos obrigatórios. Já os lixões são considerados ilegais e agressivos a natureza. A cidade de São Paulo não possui lixões reconhecidos pela prefeitura (Dados coletados no site da Prefeitura de São Paulo www.capital.sp.gov.br em outubro e novembro de 2016 e atualizado em janeiro de 2017).

O Plano de Gestão Integrada de Resíduos Sólidos da Cidade de São Paulo PGIRS - exige dos governos, das empresas e dos cidadãos a recuperação ao máximo dos diversos tipos de resíduos recicláveis, sejam eles responsabilidade pública ou privada, e dispor o mínimo em aterros sanitários.

A diretriz fundamental que norteia o plano é a observação da seguinte ordem de prioridade: não geração, redução, reutilização, reciclagem, tratamento dos resíduos sólidos e disposição final ambientalmente adequada apenas dos rejeitos, bem como na implementação de um plano municipal de educação ambiental, com forte ênfase nos resíduos, e em programa de educação ambiental permanente voltado para a conscientização sobre a importância da não geração de resíduos, sua redução e reutilização, e em orientações a respeito da reciclagem, tratamento de resíduos e disposição final adequada dos rejeitos.

Da mesma forma, os objetivos gerais do PGIRS não diferem daqueles traçados pela Política Nacional de Resíduos Sólidos (PNRS): proteção da saúde pública e da qualidade ambiental, o estímulo à adoção de padrões sustentáveis de produção e consumo de bens e serviços, incentivo à indústria da reciclagem, a gestão integrada de resíduos sólidos, a capacitação técnica continuada na área de resíduos sólidos, a regularidade, continuidade, funcionalidade e universalização da prestação dos serviços públicos de limpeza urbana e de manejo de resíduos sólidos, a prioridade, nas aquisições e contratações governamentais, para produtos reciclados e recicláveis, a integração dos catadores de materiais reutilizáveis e recicláveis nas ações que envolvam a responsabilidade compartilhada pelo ciclo de vida dos produtos.

Os Resíduos Sólidos Domiciliares Secos (RSD Secos) constituem parcela significativa da massa de resíduos sólidos gerados pelas atividades humanas. São classificados como resíduos recicláveis ou reutilizáveis, de acordo com as definições 
estabelecidas na PNRS. Constituem-se de materiais como papel, papelão, vidro, metais (ferrosos ou não ferrosos) e plásticos (moles ou duros) e, também, de alguns produtos industrializados após o término de sua vida útil.

Apesar de não se configurar como a maior fração, os resíduos sólidos secos atingem cerca de 1/3 da massa total de resíduos coletada nos domicílios. Dados de caracterização dos resíduos coletados nas residências da cidade de São Paulo apontam para valores além dos $30 \%$ para os RSD Secos.

No ano de 2010, o Brasil coletou, na massa total de resíduos, uma fração correspondente a 32\% do total, caracterizada como RSD Secos. Ainda segundo estas fontes, do volume total de RSD, apenas 10,3\% são recuperados atualmente. Ou seja, quase 40 mil toneladas ainda estão sendo destinadas aos aterros sanitários ou a lixões, sem que sejam destinadas a rotas voltadas ao seu reaproveitamento ou reciclagem. (Dados coletados na publicação Panorama dos Resíduos Sólidos Secos de 2015 - ABRELPE 2015).

Destes índices, decorrem os dados específicos para cada material, com destaque especial para as embalagens. Pelos dados disponívei, dos resíduos sólidos recuperados, o maior percentual de recuperação se dá com o alumínio $(98,5 \%)$, seguido do papelão (72,7\%), plástico (56,8\%), vidro (49,9\%) e aço $(49,2 \%)$. Estes resultados demonstram $o$ potencial de crescimento da reciclagem e do reaproveitamento dos resíduos sólidos secos, desde que melhor estruturada a cadeia econômica e suas etapas (Dados coletados na publicação Panorama dos Resíduos Sólidos Secos de 2015 - ABRELPE 2015).

A embalagem de pizza que conhecemos não pode ser reciclada. O óleo e a gordura da pizza dificultam o processo de reciclagem, pois ficam impregnados no papelão das caixas. Quando uma embalagem de papelão abriga qualquer alimento que possa manchá-la com gordura, ou algo similar, ela deixa de ser apropriada para reciclagem, apesar de muitas caixas desses alimentos aparecerem com o símbolo indicando a possibilidade de reciclagem.

O processo de reciclagem do papel/papelão consiste em misturá-lo com água e formar uma pasta que, depois de seca, transforma-se em uma nova folha ou embalagem. Com o óleo presente nas caixas de pizza, fica impossível formar essa pasta, exceto no caso das caixas de pizza congeladas que não tem o problema do óleo. 


\section{Lixo em Números}

O indicador médio da despesa total do município com o manejo dos resíduos sólidos urbanos, quando rateada pela população urbana, resulta em um valor anual de $\mathrm{R} \$ 109,96 /$ habitante no Brasil. Parte de um patamar de $\mathrm{R} \$ 93 /$ habitante nas regiões Norte e Sul, alcança os $\mathrm{R} \$ 105 /$ habitante nas regiões Nordeste e Centro-Oeste e chega a $\mathrm{R} \$ 119 /$ habitante na Sudeste (Dados coletados no site do SINIR http://sinir.gov.br em outubro e novembro de 2016).

De acordo com dados divulgados pela PGIRS, do orçamento previsto para 2014, $R \$ 2,01$ bilhões ( $R$ \$ 14 mensais/hab) foram despendidos com a gestão dos resíduos sólidos, sendo: $\mathrm{R} \$ 947$ milhões para pagamento de dois contratos de concessão (Ecourbis e Loga); R 893 milhões para pagamento de serviços de limpeza urbana; $\mathrm{R} \$ 27$ milhões para apoio aos catadores de materiais recicláveis; $\mathrm{R} \$ 87$ milhões para pagamento de manejo de resíduos inertes e $R \$ 59$ milhões para investimento e custeio, sem considerarem os custos de limpeza de córregos e piscinões feitos pelas subprefeituras (Dados coletados no site da Prefeitura de São Paulo www.capital.sp.gov.br em outubro e novembro de 2016 e atualizado em janeiro de 2017).

Entre os resíduos de responsabilidade pública, os mais relevantes são os de origem domiciliar, para os quais as análises comprovam a predominância da fração orgânica - na média da cidade: $51 \%$ são resíduos compostáveis, 35\% são resíduos secos recicláveis e 14\% são rejeitos. Em 2012 foram 20,1 mil toneladas por dia de resíduos sólidos, sendo 10,5 mil toneladas de resíduos domiciliares, 296 toneladas provenientes de feiras livres, 1,14 mil toneladas de resíduos da limpeza de ruas e logradouros, 2,2 mil toneladas de limpeza das estruturas de drenagem, 805 toneladas de lodos das estações de tratamento de esgotos, 4,3 mil toneladas diárias de entulhos, 619 toneladas de resíduos volumosos, 137 toneladas de poda, e 101,3 de resíduos de saúde. Do ponto de vista das quantidades, a geração média per capita de resíduos domiciliares em São Paulo em 2012 foi de 1,1 quilos por habitante por dia (Dados coletados no site da Prefeitura de São Paulo www.capital.sp.gov.br em outubro e novembro de 2016 e atualizado em janeiro de 2017).

Destaca-se também a grande concentração de empregos na região Sudeste, tanto nas prefeituras quanto nas empresas de manejo de RSU (resíduos sólidos urbanos). Onde encontra-se metade dos postos de trabalho do setor, ditada, em 
grande parte, pela presença dos municípios do Rio de Janeiro e São Paulo que, juntos, detêm 35.890 postos, 30\% do total de empregados da região (Dados coletados no site da Prefeitura de São Paulo www.capital.sp.gov.br em outubro e novembro de 2016 e atualizado em janeiro de 2017).

\section{Números do Mercado de Consumo de Pizza em São Paulo}

De acordo com o portal Wikipédia (2017), a pizza era um alimento de pessoas humildes do sul da Itália, quando, próximo do início do primeiro milênio, surgiu o termo picea, na cidade de Nápoles, considerada o berço da pizza. "Picea" indicava um disco de massa assada com ingredientes por cima. Servida com ingredientes baratos, por ambulantes, a receita objetivava "matar a fome", principalmente a da parte mais pobre da população. Normalmente, a massa de pão recebia, como sua cobertura, toucinho, peixes fritos e queijo.

A pizza chegou ao Brasil junto com os imigrantes italianos. Até 1950 este prato se restringia mais aos círculos italianos, mas a partir deste momento ela se disseminou por todo o país, tornando-se rapidamente um elemento democrático da cultura e da culinária brasileira.

Segundo a Associação das Pizzarias Unidas do Estado de São Paulo (2015):

1. O Brasil é o segundo maior mercado consumidor de pizza do mundo, só superado pelos Estados Unidos.

2. O Brasil possui, aproximadamente, 36 mil pizzarias, que geram cerca de 360 mil postos de trabalho e apresentam movimento superior a $\mathrm{R} \$ 22$ bilhões/ano.

3. No Estado de São Paulo estimam-se 11 mil pizzarias em funcionamento e movimenta $R \$ 8,5$ bilhões ao ano.

4. São Paulo é a cidade que registra o segundo maior consumo de pizzas do mundo, perdendo apenas para Nova York.

5. Na Grande São Paulo, estima-se 6,3 mil estabelecimentos. Cerca de $80 \%$ dessas empresas trabalham apenas com entregas, no sistema chamado delivery.

6. Diariamente são consumidas um milhão de pizzas no país, sendo 572 mil apenas em São Paulo. Ou seja, 57\% do total do consumo no país acontece na capital paulistana.

7. Na cidade de São Paulo o consumo médio mensal por habitante é de sete unidades por mês. 
8. Ao longo da última década, o setor vem tendo um crescimento médio anual superior a $5 \%$.

9. São mais de 230 tipos de pizza, entre salgadas e doces. Os tipos mais consumidos são: mussarela, margherita, quatro queijos.

10. Os empregos diretos gerados pelas pizzarias somam 29.200; os indiretos, 20.300 e os terceirizados 74.300 .

\section{Números das embalagens de pizza}

As embalagens de pizza usadas atualmente no Brasil são feitas de papelão e para a usual pizza com oito pedaços tem o seguinte tamanho Comprimento: $355 \mathrm{~mm} \mathrm{x}$ Largura: $355 \mathrm{~mm}$ x Altura: $50 \mathrm{~mm}$.

Considerando essas dimensões valem as seguintes análises:

1. Considerando os dados mencionados anteriormente sobre o consumo de 572 mil pizzas por dia na cidade e que $80 \%$ desse volume são delivery pode-se concluir que são geradas diariamente 457.600 mil embalagens de pizza que não são recicláveis.

2. Considerando que essas embalagens têm $35 \mathrm{~cm}$ de comprimento pode-se concluir que se elas fossem enfileiradas uma a uma seria possível diariamente percorrer quase 3,5 vezes as marginais Tiete e Pinheiros juntas. Já que $457.600 \mathrm{x}$ $0,00035 \mathrm{~km}=160 \mathrm{~km}$, e que as marginais tem $47 \mathrm{~km}$ de percurso total $=160 / 47$ $=3,40$.

3. Considerando que essas embalagens têm $05 \mathrm{~cm}$ de altura pode-se concluir que se elas fossem empilhadas uma a uma seria possível diariamente atingir a altura de mais de 76 Torres Eiffel (300 metros de altura cada) ou mais de 27 Edifícios como o Burj Khalifa (828 metros de altura cada) em Dubai.

Conclui-se que o volume de RSU somente das caixas de pizza é relevante e os únicos destinos possíveis são os aterros sanitários.

\section{Conclusões Finais}

Não se pode questionar a importância desse prato na cultura do brasileiro, mais ainda na cultura paulista e paulistana. A pizza tem até um dia só seu - $O$ dia da pizza que começou a ser comemorado em 1985 - o dia 10 de julho. De ditados populares a 
dia oficial, a pizza é um hábito, um senso comum, mas esse hábito não vem sozinho, vem acompanhado de um grande volume de lixo não reciclável.

Importante ressaltar que muito é falado, inclusive pela Prefeitura de São Paulo, sobre a necessidade da coleta seletiva e reciclagem, mas como vimos essas embalagens não são recicláveis, portanto esse estudo pretende propor uma mudança de hábito, de comportamento, uma mudança de foco. Não no alimento em si, mas em como ele é acondicionado. Propondo a não geração da embalagem ou na impossibilidade disso acontecer, pelo menos em curto e médio prazo, mas na geração de algo então que possa ser reciclado/reutilizado.

A Mintel - Uma das mais importantes agencias de inteligência de mercado do mundo, anunciou em 2016, as seis principais tendências que impactarão os mercados globais de embalagem durante os próximos anos e suas implicações para os consumidores e as marcas ((Dados coletados no site da Mintel www.brasil.mintel.com em outubro e novembro de 2016).

David Luttenberger - diretor global do departamento de Embalagens da Mintel disse: "Há um caminho paralelo entre as marcas que se esforçam para envolver os consumidores em um nível mais pessoal e as expectativas deles para que as embalagens forneçam essa experiência: impressão digital que cria experiências pessoais; mensagem clara no rótulo que aumenta a transparência da marca e promove confiança na compra; embalagem ecologicamente responsável, que capacita a consciência social; híbridos que oferecem benefícios funcionais e ambientais, juntamente com grande presença de prateleira; tamanho certo de embalagem que atenda às necessidades de deslocamento dos consumidores, e aplicativos que apoiam embalagens "conectadas por celulares".

De acordo com a empresa, 63\% dos consumidores dos Estados Unidos afirmaram que as embalagens reutilizáveis são um motivo chave de compras. E quando o preço e a qualidade do produto são percebidos como iguais, os consumidores irão, cada vez mais, se voltar para essas alternativas ecológicas como fator decisivo de compra.

Tomando esse dado como ponto de partida, esse estudo intenciona propor uma solução para esse problema das embalagens não recicláveis da pizza.

A empresa DMS Innovation localizada na Califórnia - EUA, propõe uma embalagem chamada de Hybrid Pizza Box, que nada mais é que uma embalagem de pizza retornável. De acordo com o site da empresa, a embalagem é produzida em 
poliestireno de alto impacto, retém o calor igual a tradicional de papelão e pode ser usada pelo menos umas 500 vezes.

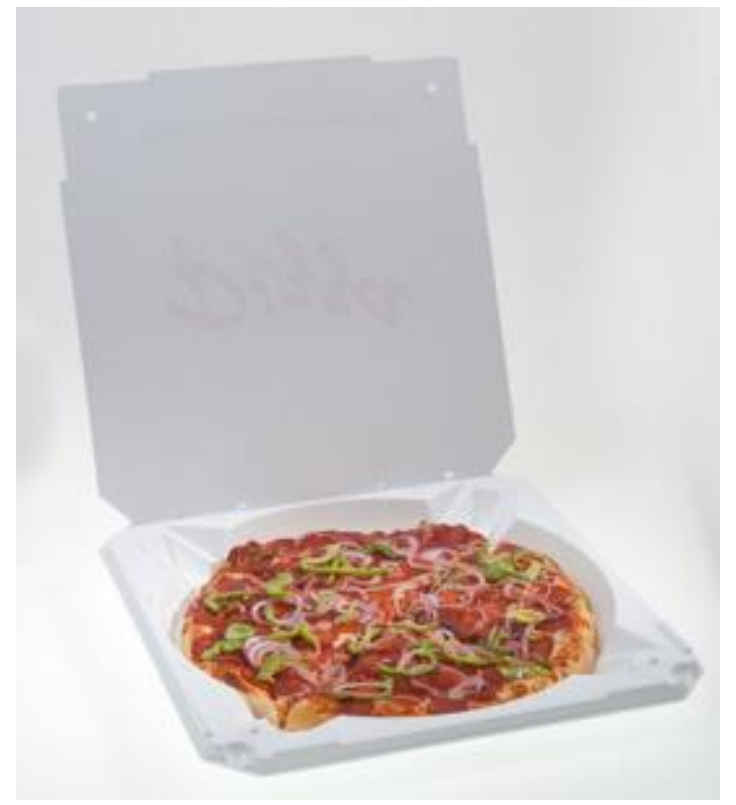

Figura 1 - Fonte Hybrid Pizza Box disponível em www.dmsinnovation.com.br (2017)

O fabricante também sugere duas formas de como seria a logística de devolução da Hybrid Pizza Box. O consumidor poderia comprar uma embalagem e a cada vez que a pizza for entregue ele troca por uma com uma pizza dentro ou poderia ter um desconto na pizza para pagar o custo da devolução da Hybrid Pizza Box. Cada caixa sai por volta de $\$ 13,00$ (dólares).

Outros dados de custo devem ser levantados para compra em grandes quantidades dessa embalagem podendo diluir significativamente o preço. Importante analisar que a mesma pode ser utilizada 500 vezes, ou seja, o custo/por vez é de U\$ $0,026 \times 3,2$ (cambio considerado) $=R \$ 0,0832$, enquanto que as embalagens tradicionais de papelão tem um custo unitário de $\mathrm{R} \$ 0,14$ (consulta eletrônica publica realizada em outubro e novembro de 2016).

Além de ser poluentes, inundarem os aterros sanitários e não serem recicláveis, os cálculos apontam que as embalagens tradicionais são $32 \%$ mais caras que a proposta da embalagem de pizza retornável.

Esse estudo não se limita a essa solução, mas sim propõe que a mesma se estenda para a comprovação ou não da aceitação pelo consumidor paulistano do uso da embalagem reciclada modelo Hybrid Pizza Box, seu uso, limpeza, inclusivo em sentido de custos de limpeza, e armazenamento doméstico. 


\section{Referências Bibliográficas}

COLETA DE LIXO. Anais eletrônicos. São Paulo: Out. 2016. Disponível em: http://www.prefeitura.sp.gov.br/cidade/secretarias/servicos/coleta_de_lixo/index.php?p= 4634. Acesso em: 10 nov. 2016.

AMLURB. Anais eletrônicos. São Paulo: Out. 2016. Disponível em:

http://www.prefeitura.sp.gov.br/cidade/secretarias/servicos/amlurb/noticias/?p=169047. Acesso em: 10 nov. 2016.

PGIRS (Plano de Gestão Integrada de Resíduos Sólidos da Cidade de São Paulo). Anais eletrônicos. São Paulo: Out. 2016. Disponível em:

http://www.prefeitura.sp.gov.br/cidade/secretarias/upload/servicos/arquivos/PGIRS2014.pdf. Acesso em: 10 nov. 2016.

ATERRO SANITÁRIO. Anais eletrônicos. São Paulo: Out. 2016. Disponível em: https://www.significados.com.br/aterro-sanitario/. Acesso em: 10 nov. 2016.

CHORUME. Anais eletrônicos. São Paulo: Out. 2016. Disponível em: https://www.significados.com.br/chorume/. Acesso em: 10 nov. 2016.

RESIDUOS SÓLIDOS. Anais eletrônicos. São Paulo: Out. 2016. Disponível em: https://www.significados.com.br/residuos-solidos/. Acesso em: 10 nov. 2016.

COLETA SELETIVA. Anais eletrônicos. São Paulo: Out. 2016. Disponível em: https://www.significados.com.br/coleta-seletiva/. Acesso em: 10 nov. 2016.

SISTEMA NACIONAL DE INFORMAÇÕES SOBRE A GESTÃO DOS RESÍDUOS SÓLIDOS. Anais eletrônicos. São Paulo: Out. 2016. Disponível em: http://sinir.gov.br/. Acesso em: 10 nov. 2016. 
ABRELPE 2015 - PANORAMA DOS RESIDUOS SOLIDOS NO BRASIL. Anais eletrônicos. São Paulo: Out. 2016. Disponível em: http://www.abrelpe.org.br/Panorama/panorama2015.pdf. Acesso em: 10 nov. 2016.

SAIBA POR QUE CAIXAS DE PIZZA NÃO SÃO RECICLAVEIS. Anais eletrônicos. São Paulo: Out. 2016.2 Disponível em: http://www.ecycle.com.br/component/content/article/35/1817-saiba-por-que-caixas-depizza-nao-sao-reciclaveis.html. Acesso em: 10 nov. 2016.

CAIXA DE PIZZA RETORNÁVEL. Anais eletrônicos. São Paulo: Out. 2016. Disponível em: http://blog.pedidor.com/embalagens/caixa-de-pizza-retornavel.html. Acesso em: 10 nov. 2016.

UM MILHÃO DE PIZZAS SÃO CONSUMIDAS POR DIA EM SP. Anais eletrônicos. São Paulo: Out. 2016. Disponível em: http://g1.globo.com/sao-paulo/noticia/2012/03/cercade-1-milhao-de-pizzas-sao-consumidas-por-dia-em-sp.html. Acesso em: 10 nov. 2016.

PIZZAS VENDIDAS $x$ NUMERO DE HABITANTES $X$ NUMEROS DE CONCORRENTES. ROMEO, R.; Anais eletrônicos. São Paulo: Jan. 2015. Disponível em: http://www.profissionaisdacozinha.com.br/index.php?/topic/2122-pizzas-vendidasx-numero-de-habitantes-x-numeros-de-concorrentes/. Acesso em: 10 nov. 2016.

A TERRA DA PIZZA: SÃO PAULO CONSOME MAIS DA METADE. Anais eletrônicos. São Paulo: Out. 2016. Disponível em: http://www.ecdfoodservice.com.br/midia/a-terrada-pizza-sao-paulo-consome-mais-da-metade/. Acesso em: 10 nov. 2016.

ESTUDO MACROECONÔMICO DA EMBALAGEM ABRE/ FGV. Anais eletrônicos. São Paulo: Out. 2016. Disponível em: http://www.abre.org.br/setor/dados-de-mercado/. Acesso em: 10 nov. 2016. 
EMBALAGENS. Anais eletrônicos. São Paulo: Out. 2016. Disponível em: http://portal.anvisa.gov.br/embalagens. Acesso em: 10 nov. 2016.

SÃO PAULO RECICLA POUCO MAIS DE $1 \%$ DE TODO LIXO PRODUZIDO DIARIAMENTE. Anais eletrônicos. São Paulo: Jun. 2012. Disponível em:

http://memoria.ebc.com.br/agenciabrasil/agenciabrasil/noticia/2012-06-21/sao-paulorecicla-pouco-mais-de-1-de-todo-lixo-produzido-diariamente. Acesso em: 10 nov. 2016.

COMO AUMENTAR AS VENDAS DE SUA PIZZARIA EM PLENA CRISE. Anais eletrônicos. São Paulo: Jan. 2016. Disponível em: http://expressodelivery.com.br/blog/como-aumentar-as-vendas-da-sua-pizzaria-emplena-crise/ . Acesso em: 10 nov. 2016.

UM MILHÃO DE PIZZAS SÃO CONSUMIDAS TODOS OS DIAS NO BRASIL. Anais eletrônicos. São Paulo: Jun. 2016. Disponível em: http://www.jb.com.br/cultura/noticias/2016/06/25/1-milhao-de-pizzas-sao-consumidastodos-os-dias-no-brasil/. Acesso em: 10 nov. 2016.

ESTE É O 1ํ RESTAURANTE COM COMIDA EM IMPRESSÃO 3D DO MUNDO. BARBOSA, D.;. Anais eletrônicos. São Paulo: Jul. 2016. Disponível em: http://exame.abril.com.br/estilo-de-vida/este-e-o-10-restaurante-com-comida-emimpressao-3d-do-mundo/. Acesso em: 10 nov. 2016.

PIZZA VENDE. Anais eletrônicos. São Paulo: Out. 2016. Disponível em: http://www.pizzavende.com.br/. Acesso em: 10 nov. 2016.

FOOD INK. Anais eletrônicos. São Paulo: Out. 2016. Disponível em: http://foodink.io/. Acesso em: 10 nov. 2016.

DADOS DA CIDADE DE SÃO PAULO. Anais eletrônicos. São Paulo: Jan. 2016. Disponível em: http://www.visitesaopaulo.com/dados-da-cidade.asp . Acesso em: 10 nov. 2016. 
SEIS TENDENCIAS EM EMBALAGENS QUE IMPACTARÃO O MERCADO GLOBAL. Anais eletrônicos. São Paulo: Dez. 2015. Disponível em: http://brasil.mintel.com/imprensa/alimentos-e-bebidas/mintel-anuncia-as-seistendencias-em-embalagem-que-impactarao-os-mercados-globais-em-2016. Acesso em: 10 nov. 2016.

PIZZA. Anais eletrônicos. São Paulo: Dez. 2015. Disponível em: https://pt.wikipedia.org/wiki/Pizza. Acesso em: 10 nov. 2016.

MARTINS, E.; MANUAL DE REDAÇÃO DO JORNAL O ESTADO DE SÃO PAULO. 3 ed. São Paulo: Estado de São Paulo, 1997.

Hempe, C., \& Noguera, J. O. C. (2012). A EDUCAÇÃO AMBIENTAL E OS RESÍDUOS SÓLIDOS URBANOS. REVISTA ELETRÔNICA EM GESTÃO, EDUCAÇÃO E TECNOLOGIA AMBIENTAL 5(5). 682-695. Doi.org/10.5902/223611704117.

Thomas, J. M. (2010). ECONOMIA AMBIENTAL: FUNDAMENTOS, POLÍTICAS E APLICAÇÕES. São Paulo: Cengage Learning. (Da Biblioteca da FMU).

Gil, A. C. (2002). Como elaborar projetos de pesquisa. (4a ed). São Paulo: Atlas. 